$7-2009$

\title{
Bond to Society, Collectivism, and Conformity: A Comparative Study of Japanese and American College Students.
}

\author{
Miyuki Fukushima \\ Cleveland State University, m.fukushima@csuohio.edu \\ Susan F. Sharp \\ University of Oklahoma Norman Campus \\ Emiko Kobayashi \\ Kanazawa University
}

Follow this and additional works at: https://engagedscholarship.csuohio.edu/clsoc_crim_facpub

Part of the Race and Ethnicity Commons, Social Control, Law, Crime, and Deviance Commons, and the Sociology of Culture Commons

How does access to this work benefit you? Let us know!

\section{Publisher's Statement}

This is an Author's Accepted Manuscript of an article published in Deviant Behavior, July 2009, available online: http://www.tandfonline.com/10.1080/01639620802296212.

\section{Repository Citation}

Fukushima, Miyuki; Sharp, Susan F.; and Kobayashi, Emiko, "Bond to Society, Collectivism, and Conformity: A Comparative Study of Japanese and American College Students." (2009). Sociology \& Criminology Faculty Publications. 101.

https://engagedscholarship.csuohio.edu/clsoc_crim_facpub/101

This Article is brought to you for free and open access by the Sociology \& Criminology Department at EngagedScholarship@CSU. It has been accepted for inclusion in Sociology \& Criminology Faculty Publications by an authorized administrator of EngagedScholarship@CSU. For more information, please contact library.es@csuohio.edu. 


\title{
bond to society, collectivism, and conformity: a comparative study of Japanese and American college students
}

\author{
Miyuki Fukushima and Susan F. Sharp \\ Department of Sociology, University of \\ Oklahoma, Normal, Oklahoma, USA
}

\section{Emiko Kobayashi}

Foreign Language Institute, Kanazawa University, Kanazawa, Japan

An argument is developed that the purported collectivism in Japanese society generates stronger social bonds in Japan than in the more individualistic United States, which might then explain the lower level of deviance often found in Japan. We test this using survey data from samples of Japanese and American college students on measures of deviance and social bonds. Results indicate that Japanese students engage in significantly less deviance than Americans, and

Funding for the surveys reported was provided by the College of Arts and Sciences, University of Oklahoma and by Grant-in-Aid for Scientific Research \#16730274 from the Japanese Ministry of Education, Culture, Sports, Science and Technology (Emiko Kobayashi, investigator).

An earlier version of this article was presented at the Annual Meeting of the Southwestern Social Science Association in 2005. We are most grateful to Dr. Harold G. Grasmick for his contributions to collecting the U.S. data and his invaluable input into the manuscript. We also thank anonymous reviewers of this journal for their insightful comments and critiques.

Address correspondence to Miyuki Fukushima, Department of Sociology, University of Oklahoma, 780 Van Vleet Oval, Kaufman Hall, Room 342, Norman, OK 73019, USA. E-mail: miyuki@ou.edu 
although variables from Hirschi's (1969) social control theory behave similarly across cultures as predictors of deviance, the theory failed to account for the lower level of deviance among Japanese.

\section{INTRODUCTION}

The contrast in crime rates between Japan and the United States carries salience for comparative sociology, as Japan is a non-Western country that is relatively comparable to the United States in economic development. Scholars have repeatedly noted evidence of much lower crime rates in Japan than in the United States and other Western nations (see Adler 1983; Braithwaite 1989; Dussich et al. 2001; Gruszczynska 2002; Hendry 1989; Komiya 1999; Roberts and Lafree 2001, 2004). However, only a handful of studies (e.g., Grasmick and Kobayashi 2002; Kobayashi and Grasmick 2002; Kobayashi et al. 2001; Vazsonyi et al. 2004) have used comparable self-report data demonstrating lower levels of deviance among Japanese than Americans or used conventional theories of deviance to attempt to explain this difference.

The present study employs identical self-reported deviance measures administered to samples of Japanese and American college students in April 2003. Although our study deals with the relatively nondeviant group of college students, we nonetheless found the expected difference in the levels of deviance between the Japanese and American samples - the level of deviance measured in this study is lower among the Japanese students. Our research is guided by the literature on collectivistic and individualistic culture in comparative sociology and psychology, which we argue can be tied to Travis Hirschi's (1969) social control theory of deviance as an explanation of compliance with norms. We hypothesize that social bonds will be stronger in a collectivistic culture like Japan, leading to higher levels of compliance with norms. Our survey contains direct measures of variables from Hirschi's social control theory to test the hypothesis that Japanese engage in less deviant behavior because they are more strongly bonded than Americans to conventional society.

Hirschi (1969) argues that his social control theory is applicable in explaining deviant behaviors across groups 
and cultures and should explain differences in levels of deviance between groups (see also Chapple et al. 2005; for a similar argument concerning Gottfredson and Hirschi's more recent self-control theory, see Tittle and Botchkovar 2005) - the two important issues for comparative criminology originally raised by feminist scholars. Namely, can criminological theory (1) explain equally well delinquency/ deviance of different groups and (2) account for the differences in the level of delinquency/deviance of groups? The first issue pertains to the generalizability or applicability of a theory of deviance across diverse groups, whereas the second issue pertains to how well a theory accounts for the gap in deviance between groups. Hirschi (1969) argues that as a universal theory of deviance, his social control theory should account for both of these issues.

Some empirical studies testing Hirschi's social control theory of deviance, or part of the theory, beyond Western culture have been reported. Without exception, however, all these studies test the theory within only non-Western cultures and thus lack a comparison group from a Western culture. These studies can demonstrate only whether social bond variables affect deviance beyond Western culture or whether Hirschi's social control theory is applicable in non-Western culture (i.e., the first issue). They cannot, however, demonstrate whether social bond variables can account for differences in levels of deviance across cultures (i.e., the second issue). Using comparable data from Japanese and American college students on deviance and social bonds, our main objective is to examine the second issue, that is, can Hirschi's social control theory account for the expected gap in deviance between Japanese and American students?

\section{HIRSCHI'S SOCIAL CONTROL THEORY}

Travis Hirschi (1969) introduced a refined version of control theory into the field of deviance, building on existing control theories (cf., Reckless 1967), and focusing on the social bond. Hirschi draws a sharp distinction between control theory, which emphasizes constraints against deviance, and other theories that concentrate on factors that push people into deviance, such as Merton's anomie theory (see also 
Gottfredson and Hirschi 1990; Kornhauser 1978). For control theory, all actors are assumed to be equally motivated to transgress, but people vary in the constraints they experience that more or less prevent them from acting on this universal motivation to engage in acts of force and fraud in pursuit of their self-interest; thus, control theory is about these constraints. According to Hirschi (1969), the controls or constraints acting on individuals and preventing deviance are found in their bonds to conventional society. Deviance occurs when "[an] individual's bond to society is weak or broken" (Hirschi 1969:16). In other words, the stronger an individual's bond to society, the less likely the individual is to deviate from societal norms.

Hirschi (1969) identifies four elements of the social bond: attachment, commitment, involvement, and belief. The element of attachment is the "bond of affection" to conventional persons and institutions. Commitment refers to the "stakes in conformity that are built up by pursuit of, and by a desire to achieve, conventional goals" (Hirschi 1969:162). Involvement, as argued by Hirschi (1969:185) is "the most obviously related to delinquent behavior," for the more time people spend in conventional activities, the less time they have for delinquent and criminal activities. Finally, for Hirschi (1969:198), the element of belief in the legitimacy of law is related to deviance in that the "absence of (effective) beliefs" that forbid deviance, free one to engage in it.

A handful of studies test Hirschi's version of social control theory in Asian societies (Hwang and Akers 2003; Miller 1992; Saito 2002; Shoemaker 1994; Tanioka and Glaser 1991; Wang et al. 2002; Zhang and Messner 1995, 1996). Generally, but with exceptions, they find some evidence that in Asian samples at least some of the elements of the social bond are linked to lower levels of self-reported deviance. Notable anomalies are Zhang and Messner (1996) in China and Hwang and Akers (2003) in South Korea, who find that attachment to parents is not important to explaining selfreported deviance in these societies. In addition, in the Hwang and Akers (2003) study, the effect of attachment to peers on deviance is found to be positive, contrary to Hirschi's (1969) prediction.

The objective with our unique dataset is different from previous studies testing the theory among Asian samples. In 
comparable samples of Japanese and American college students, we measured all of the elements of the social bond, along with self-reported deviance. We expect to find lower levels of deviance among the Japanese, and we expect this to be the result of stronger social bonds among them. Though no extant studies empirically examined a direct link between individualism-collectivism and the social bond, in the next section, we point to the literature on collectivism as the rationale for our central hypothesis that Japanese youth engage in less deviant behavior than Americans because they are more strongly bonded to conventional society.

\section{COLLECTIVISM-INDIVISUALISM}

The idea that Japan, in contrast to the United States, is more collectivistic emerged in writings such as Lowell's (1888) The Soul of the Far East, published shortly after the reopening of Japan in 1854. The most widely known statement on this topic no doubt is Benedict's (1946) The Chrysanthemum and the Sword (see also Abegglen 1958). The idea that Japan tends more toward collectivism, whereas the United States tends toward individualism also gained popularity even among Japanese scholars (see Doi 1971, 1985; Kawasaki 1969; Nakane 1970).

In the 1980s, researchers, especially Hofstede (1980; Hofstede and Bond 1984; see also Hofstede 1991) in the field of cross-cultural psychology began developing measures of individualism-collectivism and using these measures to collect data from diverse cultures (see also Triandis 1988, 1990, 1995). In his seminal empirical study of IBM workers in different countries, Hofstede (1980; see also Hofstede and Hofstede 2004) reported that American workers in their work setting were significantly more individualistic on his measure than were Japanese workers.

Since Hofstede's original formulation and research, others have developed modifications of his basic idea. In the tradition of theory and research on "value orientations" (e.g., BallRokeach et al. 1984; Rokeach 1973), Schwartz (1990, 1992) conceptualized individualism-collectivism as more global "value orientations." Markus and Kitayama (1991; see also DeGooyer 1992) linked the idea to self-concept literature, distinguishing between an "independent self-concept" (i.e., 
individualism) versus an "interdependent self-concept" (i.e., collectivism). Throughout this literature, Japan, compared to the United States, is found to be collectivistic, and Japanese, compared to Americans, are considered to have more interdependent self-concepts.

Furthermore, using questionnaire items from refinements of Schwartz's (1990, 1992) and Markus and Kitayama's (1991) scales, Gudykunst et al. (1996) also reported that Japanese college students scored higher than Americans on measures of collectivistic values (e.g., harmony with others, observing rites and social rituals) and an interdependent selfconcept (e.g., "I consult with others before making important decisions," "I will sacrifice my self-interest for the benefit of my group" ${ }^{\prime \prime}$.

Our contention is that collectivism implies a stronger bond to society, and, if Hirschi's (1969) theory is correct, this should lead to less deviance in collectivistic societies like Japan than in more individualistic societies like the United States. The similarity between Hirschi's refined social control theory that focuses on the individual's bond to society (social bond) and the individualistic-collectivism dimension derives from an identical emphasis placed on the relationship between the individual and the collective society.

Individualism means placing a value on individual identity over group identity, individual needs and rights over group obligations, and individual pleasure over adherence to group norms (for a discussion of individualism in the United States, see Bellah et al. 1985). Collectivism, on the other hand, grants priority to group identity over individual identity, shared in-group beliefs over unique individual beliefs, and cooperation with in-group members over maximizing individual outcomes (see Gudykunst et al. 1996). Triandis (1988) states that members of individualist cultures are characterized by hedonism and self-seeking attitudes, suggesting weak bonds to society. Hence, we argue that collectivist cultures should be more effective in fostering social controls or constraints against deviant behavior while also fostering conformity among members of society.

Indeed, cross-cultural scholars posit that members of collectivist cultures, such as Japan's, tend to place a higher value on family, family relationships, and on relationships with others in the society, while members of individualistic 
cultures, such as America's, tend to place a higher value on independence and autonomy (see Gudykunst et al. 1996; Hofstede 1980, 1984, 1991, 2001; Matsumoto and Juang 2004; Matsumoto et al. 1996, 1997; Triandis 1988, 1999). In other words, using Hirschi's (1969) terminology, we might argue that members of collectivist cultures are more strongly attached to parents, peers, teachers, and schools.

Furthermore, the literature on collectivism suggests that the "stake in conformity," or the element of commitment, might also be higher in collectivist cultures than in individualist cultures. The greater social pressure to conform and, thus, greater potential costs (stake) from deviant behavior in collectivist cultures, should promote a higher level of commitment among their members, compared to individualist cultures, particularly in the United States where conformity is, to some extent, considered a negative attribute (Matsumoto and Juang 2004). In addition, the stronger attachment to others, coupled with the greater commitment to conventional goals, should then produce a higher level of involvement in conventional activities in collectivist cultures. Finally, members of collectivistic cultures tend to value "norms, duties, and obligations" relative to individual factors, while the members of individualistic cultures tend to value personal emotions, attitudes, and needs relative to social factors (Triandis 1999:128). It would follow, then, from Hirschi's (1969) formulation that collectivist cultures promote a stronger bond to society by generating a stronger belief in the legitimacy of the law.

The idea that the concept of the Hirschi's (1969) social bond might overlap with the concept of collectivistic versus individualist culture in cross-cultural psychology does not derive directly from his formulation of social control theory. To be clear, the concept of collectivistic-individualistic culture explains cultural variations across different groups. On the other hand, although Hirschi intended his theory to be a generalizable, universal theory to be applied to all and any groups, Hirschi's social control theory is not an explanation of between-group cultural variations (e.g., individualism-collectivism) in deviance. Furthermore, there is no extant study that directly tests the link between individualism-collectivism and social bonds, from which we could base our assumption that collectivistic culture has higher 
social bonds compared to individualistic cultures. Nevertheless, theories and research in this area outlined here lead us to reasonably infer that social bonds will be stronger in collectivistic than in individualistic cultures, which then would explain the lower level of self-reported deviance we expected and found among Japanese college students compared to Americans. Thus, our research tests the hypothesis that Japanese college students score lower than Americans on self-reported deviance because Japanese score higher on the elements of the social bond outlined by Hirschi (1969)_attachment, commitment, involvement, and belief in the legitimacy of the law.

\section{METHODS}

\section{Sample}

The data to test the hypotheses come from a survey conducted by two of the authors. The American sample consists of 505 students from a Southwestern state university who were enrolled in an introductory sociology class. The Japanese sample consists of 442 students who were enrolled in sophomorelevel classes at a comparable national university in Japan, to which one of the Japanese authors had access. The questionnaire initially was written in English and then was carefully translated and pre-tested in Japan by one of the Japanese authors. Data were collected in the two universities at the same time in April 2003. Because of the differences in academic calendars, this means that most of the American students were just finishing their freshman year, whereas the Japanese students had just began their sophomore year.

Gathering comparable survey data from college students in the two countries is not a simple task. Several issues had to be addressed concerning differences in social structure and culture, differences that affected both sample selection and measurement. To achieve comparability in ways that are important for the analysis, some cases, as explained later, had to be omitted. The final analysis to be reported is based on 433 of the Japanese students and 369 of the American students.

Data were obtained from students in two public universities - one in the United States and one in Japan. In the 
United States, this was a major state university in the Southwest to which the American authors had access. The total enrollment (graduate and undergraduate) is approximately 22,000 , and the university is within the boundaries of a metropolitan area of about 1.1 million inhabitants that also contains the state's capital.

Selecting a comparable Japanese university required several decisions. First, the term "state university" can be misleading in Japan. Each of the 47 Japanese prefectures (equivalent to states in the United States) has several prefecture- and city-financed universities, but these generally are not comparable to the major flagship universities in states in the United States. Rather, they more closely resemble regional universities within states in the United States. In addition to these Japanese prefecture- and city-financed universities, however, each prefecture has at least one national university funded by the Japanese Ministry of Education, Culture, Sports, Science and Technology. As of 2003, the year our data were gathered, there were 100 of these national universities, which are the major and prestigious, and most selective public universities in the country. These Japanese national universities are the ones most comparable to the major state universities in the United States. Consequently, the Japanese data were collected at a national university.

To select a particular national university in Japan, similarity to the U.S. metropolitan area in the Southwest and to the size of the university in the United States, were important considerations. We chose a national university in a prefecture that did not contain the largest Japanese metropolitan areas like Tokyo, Yokohama, and Osaka. Nevertheless, it is located within a metropolitan area of substantial size (2.2 million inhabitants) that contains the prefecture's capital city. The university selected has an enrollment of approximately 16,500 undergraduate and graduate students. Thus, both the American and the Japanese universities are in large (but not the largest) metropolitan areas that include the state/ prefecture capital. Although the American state university has a somewhat larger enrollment than the Japanese national university, neither is among the largest such university in their country.

We also had to address the wide discrepancy between Japanese national and American state universities in racial 
and ethnic diversity, a discrepancy so wide that "minority group" status could not be a variable in our analysis. There are essentially no "minority group" members in Japanese national universities. Had we tried to include a variable for minority group status, all Japanese respondents would have been in the same category. Consequently, our plan was to use only the questionnaires completed by Caucasian students in the United States, excluding those who were selfidentified minority group members. Because the American university's enrollment is $74 \%$ Caucasian, a total sample of 600 would have yielded about 450 Caucasians. However, one of the sections of Introduction to Sociology from which we intended to gather data became problematic, and our total U.S. sample was 505, of whom 369 (i.e., 73\%, compared to $74 \%$ in the university according to official figures) identified themselves as "white." All others have been excluded from the analysis we report.

The absence of "minorities" in Japanese national universities merits explanation. The Ministry of Public Management, Home Affairs, Posts and Telecommunications, Japan (1995) reports populations of people of non-Japanese origin, primarily Koreans, Chinese, Brazilians, and Filipinos (see also Sugimoto 2003). However, a series of laws over time has made it difficult, often impossible, for such people to obtain Japanese citizenship (Lie 2001:83-110). Even through marriage to a Japanese citizen, citizenship is not guaranteed. Furthermore, those residents without Japanese citizenship, with rare exceptions, are not eligible to attend Japanese national universities.

The Japanese government does not report figures on the number of non-Japanese permanent residents enrolled in national universities, but the number surely is low. A consequence of this policy of exclusion is that $98 \%$ of the students in our Japanese sample do not identify themselves as having non-Japanese origin. The remaining 2\% (nine students) are Japanese residents who are not Japanese citizens or nonresident students from other Asian countries. These nine are excluded from the analysis, leaving 433 useable cases in Japan. In the analysis, these will be compared to the 369 whites in the U.S. sample. In both countries, all students who were in class the day the data were collected agreed to complete the questionnaire. 


\section{Measures}

\section{Japan}

Japan is a dummy variable coded 1 for Japanese and 0 for American students. The variable has a mean of .540 and standard deviation of .498. We expect the variable Japan to have an inverse effect on our measure of self-reported deviance described later, even when other variables, also described later, are controlled.

\section{Self-Reported Deviance}

The dependent variable consists of 13 items measuring various non-drug related deviant behaviors ranging from "Hurt someone badly enough that they needed bandages or a doctor" to "Cheated in school to get a better grade." Students were asked to indicate how often they have engaged in the 13 deviant behaviors in the past year using a five-point Likert scale with responses ranging from "Never" to "Almost always." Items are coded so that a higher value indicates a higher level of deviance, with values ranging from 0 to 4 .

Before creating a single deviance scale from the combined samples, we assessed the possibility that the dimensionality of deviance is not the same in the two countries. In both cases, however, the eigenvalues indicated unidimensionality, and the reliability coefficients were both identically high (.763 in Japan and .812 in the United States).

These analyses suggest that we can be justified in creating a single deviance scale from the combined samples. A principal components analysis for the 13 items indicates a single factor. Cronbach's alpha for the linear composite of $z$-scores of the 13 items is .79. Reliability could not be improved by eliminating any of the items. The deviance scale was created by summing the $z$-score transformations of the all items, producing a deviance scale for the combined sample with a mean of 0 and standard deviation of 7.07.

\section{Control Variables}

Four control variables generally thought to be relevant in studies of deviance are included in the analyses, including respondent's age, gender, parental socioeconomic status, and family structure. A preliminary analysis of the age 
distribution of the combined sample shows that the distribution is positively skewed ( $\mathrm{kk}=+4.26)$. This is due to a small number of outliers in the American sample who are much older than average college students (e.g., sk for the American sample is +3.52 and for the Japanese sample is +1.81$)$. In order to reduce the skewness of the distribution of age, particularly among the American sample, the log of the variable age for the combined sample is created by taking the natural log of each student's actual age. The new distribution of logage shows a slight reduction in skewness $(s k=+2.93)$ with a mean of $1.29(S D=.023)$.

Respondents' gender is a dummy variable called Male with males coded as 1 and females coded as 0 . The variable Male has a mean of $.58(S D=.49)$. It should be noted that the two samples differ significantly in percent male $(43 \%$ in the United States and $71 \%$ in Japan). The figures from the Japanese Ministry of Education, Culture, Sports, Science, and Technology (2003) indicate that $66 \%$ of the total students who enrolled in Japanese national universities are male, whereas $71 \%$ of students who were enrolled in the university, where the data were collected, were male. Although the gender distribution of students in the Japanese sample is consistent with the actual gender distributions found in Japanese national universities overall, it differs greatly from that of the American sample. Because gender is related to Japan, and also likely related to deviance, gender is a possible source of spurious relationships between nationality and deviance, thus must be controlled throughout the analysis.

The respondents' parental socioeconomic status is measured by combining both parents' attained education levels. To measure parents' education levels, students were asked to indicate the highest level of education attained by his or her parent or parents. The variable Parents' Education is an ordinal variable with five categories, coded so that a higher value indicates higher parental education attainment, including "neither parent has a high school degree" (coded 1), "one or both parents have a high school degree but no higher" (coded 2), "one or both parents have more than a high school degree but less than a college degree" (coded 3), "one or both parents have a college degree but no higher" (coded 4), and "one or both parents have a graduate or professional degree" (coded 5). The distributions of this variable 
differ by country, and indicate a slightly higher overall parental educational attainment for the American sample compared to the Japanese sample. While the percentages of students with at least one parent with a college degree or higher were identical across countries $(67.21 \%$ for Americans and $68.29 \%$ for Japanese), the percentages of students with at least one parent with a graduate or a professional degree $(32.52 \%$ and $9.70 \%$, respectively) and the percentages of students with both parents having only a high school degree or lower $(8.13 \%$ and $21.48 \%$, respectively) differ substantially.

To measure family structure, students were asked: "While you were growing up, how would you describe your household?" The Two-Parent Home variable in the analysis is a dummy variable. Those students indicating that they had, at any time in their lives, experienced being in a single-parent home (i.e., "single mother household" and "single father household") received a value of 0 . All other students, that is, those students who had never experienced a single-adult household and lived their entire lives in households with more than one adult present, received a value of 1 . The mean for the Two-Parent Home variable for the combined sample is .91 $(S D=.29)$, indicating that $91 \%$ of students have never experienced a single-parent household. The distribution differs slightly by nationality. While the mean for the Japanese sample is .95 $(S D=.21)$, the respective mean for the American sample is $.85(S D=.36)$, indicating a slightly larger proportion of American than Japanese students who have experienced a single-parent home.

\section{Social Bonds}

Measures of social bond elements include attachment to others, commitment to conventional goals, involvement in conventional activities, and belief in the legitimacy of the law. Attachment includes caring about (1) parents, (2) peers, and (3) school. In Hirschi's original formulation, attachment to, or caring about the feelings of parents has three subcomponents: (a) identification with and affection toward parents, (b) intimate communication, and (c) parental supervision. Because of Kempf's (1993) observation of inconsistencies in how social bond variables have been measured by researchers, we tried as much as possible to use measures 
identical to those used by Hirschi's (1969) original research. The analysis includes all four elements of Hirschi's (1969) social bonds and all three dimensions of attachment. All elements of social bonds are coded so that a higher value indicates a higher level of social bond and missing cases are replaced with the mean.

Attachment to parents has three dimensions. Affectional identification was measured with three items ("I want to be like my parents"; "I feel extremely close to my parents"; and "I get all the affection I want from my parents") with an alpha of .81 for the linear composite of $z$-scores. Intimacy of communication consists of two items, "I often engage in leisure activities with my parents" and "My parents are willing to listen when I need to talk about my worries or problems," whose z-scores are summed to form a scale with an alpha of .72. Finally, alpha was .86 for the sum of z-scores for the two items measuring parental supervision ("How often did your parents figure know where you are when you are away from home?" and "How often did your parents know whom you were with when you were away from home?").

With the goal of parsimony, we further examined the possibility of creating an overall scale of attachment to parents with these three scales. The result of a reliability analysis for a linear composite of the three, however, could not justify the creation of this single overall scale of attachment to parents. Instead, the "attachment to parents" scale is the sum of the $z$-scores of affectional identification and intimacy of communication (alpha $=.87$ ), leaving "parental supervision" as a separate variable (alpha $=.86$ ).

The attachment to peer scale, with an alpha of .66, is created by combining the $z$-score transformation of two items "Do you respect your close friends' opinions about the important things in life?" and "Would you like to be the kind of person your close friends are?" The single item measuring students' attachment to school is, "In general, did you like or dislike high school?" High school, rather than college, was chosen as the frame of reference because students in both American and Japanese samples were rather early in their college careers and, thus, might not have solidified views about attachment to college.

Commitment is measured by students' reports of the importance they attach to three goals: getting good grades 
in college, graduating from college, and attaining a good job. A principal component analysis for these three items indicates a single factor, with eigenvalues of $2.05, .58$, and .37. The commitment scale then is created by summing the $z$-score transformation of these three items (alpha $=.75$ ).

The involvement variable is measured by the overall time spent in organizations or activities per week. The total of seven types of activities includes working at a job, participation in community organizations, and involvement in school activities such as athletics and band. Students were asked how many hours per week they spent in each of these, and their responses were summed to form the involvement scale. The mean of "involvement" for the combined sample is 22.31 hours per week with the standard deviation of 15.88.

The scale for "belief" is created from four items used in Hirschi's (1969) original study that measure students' level of agreement/disagreement to statements such as "it is all right to get around the law if you can get away with it." These items indicate students' belief in the legitimacy of laws and general rules. The principal components analysis supports a creation of a single factor, with eigenvalues of $2.08, .77, .64$, and .52. Cronbach's alpha for the linear composite of the $z$-scores of these four items is .69 .

\section{ANALYSIS AND RESULTS}

The analysis begins with the regression of self-reported deviance on Japan to examine whether or not the popular notion of a higher compliance among Japanese compared to Americans would hold in our samples, with controls for age, gender, parents' education level, and two-parent home shown in Table 1. The direct effect of Japan on self-reported deviance is $\beta=-.310$, indicating that Japanese score significantly lower on self-reported deviance than do the Americans. The only other variable with a larger effect is Male $(\beta=.335)$. Gender often is considered one of the strongest, if not the strongest, predictor of deviance. A comparison of the two coefficients in Table 1 suggests that the effect of being Japanese on reducing deviance is more than $90 \%$ as great as the effect of being male on increasing it. In Table 1 , the only other variable with a significant direct effect is Age, with a $\beta=.102$, suggesting that in the sample 
TABLE 1 OLS Regression of Deviance on Japan and Control Variables, $n=802$ (One-Tailed Significance Tests)

\begin{tabular}{lrrc}
\hline Variable & \multicolumn{1}{c}{$b$} & \multicolumn{1}{c}{ Beta } & \multicolumn{1}{c}{$p$} \\
\hline Japan & -4.396 & -0.310 & 0.000 \\
Male & 4.803 & 0.335 & 0.000 \\
Age & 30.715 & 0.102 & 0.001 \\
Parents' education & -0.061 & -0.008 & 0.400 \\
Two-parent home & -0.532 & -0.022 & 0.255 \\
Constant & -39.306 & & \\
$\mathrm{R}^{2}$ & 0.174 & & \\
$p$ & 0.000 & & \\
\hline
\end{tabular}

of fairly young college students, Age has a significant positive effect on self-reported deviance. In the equation, $17.4 \%$ of the variance of deviance is explained by the five variables, and nearly all of these come from just two variables, Japan and Male.

In the next analysis, shown in Table 2, we test our central hypothesis that Japanese have higher levels of social bonds compared to Americans. The results reveal that, contrary to our expectation, the Japanese students do not score consistently higher on the social bond variables than the American students. In fact, for many of the social bond variables, contrary to our expectation from the individualism-collectivism literature, Japanese youth seem to be less strongly bonded to conventional society than are their American counterparts, at

TABLE 2 Partial Correlations between Japan and Social Bonds, $n=802$ (One-Tailed Significance Test)

\begin{tabular}{lrc}
\hline Variables & Partial correlations & $p$ \\
\hline Attachment to parents & -0.497 & 0.000 \\
Parental supervision & -0.345 & 0.000 \\
Attachment to peers & -0.532 & 0.000 \\
Attachment to school & 0.100 & 0.002 \\
Involvement & -0.257 & 0.000 \\
Commitment & -0.397 & 0.000 \\
Belief & 0.051 & 0.076
\end{tabular}


least using our measures. Table 2 reports partial correlations between Japan and each of the seven social bond variables, with controls for gender, age, parents' education, and two-parent home. Based on the collectivism literature, we predicted these partial correlations to be positive and significant, suggesting that, with appropriate controls, Japanese are more strongly bonded to conventional society than are Americans.

In fact, the only significant positive partial correlation is for Attachment to School. The partial correlation for Belief also is positive but fails to achieve significance at the .05 level $(p=.076)$. For all other social bond variables, Japanese display much weaker bonds than Americans. For Attachment to Parents, Parental Supervision, Attachment to Peers, and Commitment, the partial correlations are not only significant in the direction opposite of expectations, but also they are substantial in magnitude $(-.497,-.345$, -.532 , and -.397). In other words, contrary to our hypothesis, Japanese score significantly lower on these social bonds, and the percent of variance in these bonds explained by the Japan dummy variable ranges from $13.5 \%$ to $34.1 \%$. The results indicate that the Japanese students engage in a lower level of deviance than Americans, despite their significantly weaker social bonds compared to their American counterparts.

We now have only slight evidence that Hirschi's social control theory could account for the gap in deviance found in samples of the Japanese and the American students. Nonetheless, the issue of how well each social bond variable explains deviance in the two countries still remains an important question. Thus, in Table 3, we add social bond variables into the original regression equation presented in Table 1. Table 3 shows that with the social bond variables in the equation, the standardized coefficient for Japan in Table 1 of -.310 is reduced to -.262 . In other words, the social bond variables account for only about $15 \%$ of the effect of Japan on deviance, net of the control variables, and the effect of Japan with the social bond variables in the equation remains significant. Meanwhile, the social bond variables appear to account for more of the effect of Male $(27 \%)$ than the effect of Japan, although in Table 2, the effect of Male $(\beta=.244)$ also remains significant. 
TABLE 3 OLS Regression of Deviance on Japan, Control Variables, and Social Bonds, $n=802$ (One-Tailed Significance Tests)

\begin{tabular}{lrrr}
\hline Variable & \multicolumn{1}{c}{$b$} & \multicolumn{1}{c}{ Beta } & $p$ \\
\hline Japan & -3.719 & -0.262 & 0.000 \\
Male & 3.501 & 0.244 & 0.000 \\
Age & 21.488 & 0.072 & 0.009 \\
Parents' education & -0.004 & -0.001 & 0.493 \\
Two-parent home & -0.409 & -0.017 & 0.289 \\
Attachment to parents & 0.056 & 0.032 & 0.196 \\
Parental supervision & -0.318 & -0.084 & 0.006 \\
Attachment to peers & 0.117 & 0.029 & 0.216 \\
Attachment to school & 0.166 & 0.015 & 0.309 \\
Commitment & -0.060 & -0.021 & 0.264 \\
Involvement & 0.060 & 0.134 & 0.000 \\
Belief & -0.925 & -0.376 & 0.000 \\
Constant & -29.101 & & \\
$\mathrm{R}^{2}$ & 0.340 & & \\
$p$ & 0.000 & & \\
\hline
\end{tabular}

The ability of the social bond variables to account for only $15 \%$ of the effect of Japan is disappointing in light of our hypothesis, but expected from our findings in Table 2 that Japanese have less strong social bonds than Americans. The results from the regression analysis with social bond variables further provides evidence that the Japanese students commit lower level of deviance than Americans despite their lower levels of social bonds. Thus, contrary to Hirschi's contention, his social control theory fails to account for the differences in levels of deviance found between the Japanese students and American students.

It is possible that social bonds failed to reduce the effect of Japan on deviance because all the preexisting variations in the two countries are not accounted for in the analysis. That is, it is possible that the variable Japan not only reflects the cultural variation of collectivism-individualism, thus hypothesized differences in levels of social bonds, but it also subsumes many other preexisting variations between Japan and the United States, such as levels of inequality (Bradshaw and Wallace 1996), availability of firearms (Adler et al. 2004), community policing (Cole and Smith 2001; Thornton 
and Endo 1992), homogeneity (Kerbo and McKinstry 1995), among other factors. It could be the case that the variable Japan reflects more strongly these other preexisting variations than the difference in collectivism-individualism and social bonds. If so, then even if collectivism-individualism reflects Hirschi's social bonds, social bond variables by themselves might explain a very small portion of the effect of Japan on deviance. Nonetheless, the fact still remains that although Japanese report weaker social bonds than Americans, they commit lower levels of deviance than Americans.

Additionally, the fact that there is not a greater reduction of the effect of Japan on deviance when social bonds are included (in the analysis) can be attributed to two other factors. First, some of the social bond variables (Attachment to Parents, Attachment to Peers, Attachment to School, and Commitment) do not have significant negative effects on deviance. Indeed, one of them (Involvement) actually has a positive effect on deviance. A positive effect of involvement was also found in Hirschi's (1969) study as well as other studies (e.g., Chaiken 2000; Ploeger 1997). Thus, to some extent, the failure of the social bond variables to account for most of the effect of Japan on deviance can be attributed to the absence of significant inverse effects of the social bond variables on self-reported deviance. Only Parental Supervision $(\beta=-.084)$ and Belief $(\beta=-.376)$ have significant inverse effects on self-reported deviance, as Hirschi (1969) originally predicted.

One possibility we explored, and the second factor that might also explain why the reduction of the effect of Japan on deviance is not greater, is that social bond variables do not have the same effects in Japan as they do in the United States - the issue of generalizability of theory across groups - a possibility that would be masked in Table 3 where the two samples are combined. In Table 4, therefore, we report the effects of each of the social bond variables on self-reported deviance separately for Japanese and Americans. The coefficients in the table include controls for Male, Age, Parents' Education, and Two-Parent Home. Using the statistical test discussed in Paternoster, Brame, Mazerolle, and Piquero (1998), the table also includes a test of the significance of the difference between the Japanese and the American samples in the value of unstandardized coefficient 
for each social bond variables, which resembles a test of interaction effects.

Table 4 shows that in both equations, Attachment to Parents and Attachment to School have nonsignificant effects, and the difference between Japanese and Americans is not significant. Parental Supervision has the expected significant inverse effect on deviance among Japanese, while the effect of Parental Supervision is negative but barely fails to achieve significance $(p=.055)$ among the Americans. The difference in the $b$ for Japanese and Americans, however, is not significant.

The greatest discrepancy across groups occurs for Attachment to Peers. Among the Japanese, Attachment to Peers has a significant positive effect on self-reported deviance $(p=.001)$, an effect inconsistent with the basic premise of Hirschi's argument but similar to the findings of Hwang and Akers (2003) in South Korea. Among the Americans, however, the effect of Attachment to Peers fails to achieve significance. Furthermore, the difference between the effects of attachment to peers on deviance for the Japanese and the Americans is significant $(p=.009)$.

The separate findings for Japanese and Americans for Commitment, Involvement, and Belief mirror the findings for the sample as a whole. Commitment does not have a significant effect in either group, and the difference in the effect between groups is not significant. For both Japanese and Americans, Involvement has a significant positive effect on self-reported deviance as it did in the combined sample in Table 2. Belief, as was true in the combined sample, has a significant inverse effect for both Japanese and Americans, consistent with Hirschi's (1969) argument, although the magnitude of the effect is significantly less among Japanese than among Americans.

In summary, it appears that the failure of the social bond variables to account for much of the effect of Japan on self-reported deviance cannot be attributed to any peculiarities in the effects of these variables among Japanese respondents. With the exception of the significant positive effect of Attachment to Peers among Japanese, the social bond variables behave remarkably similarly among the Japanese as they do among the Americans, adding evidence to the generalizability of this theory across culture. In effect, with the 


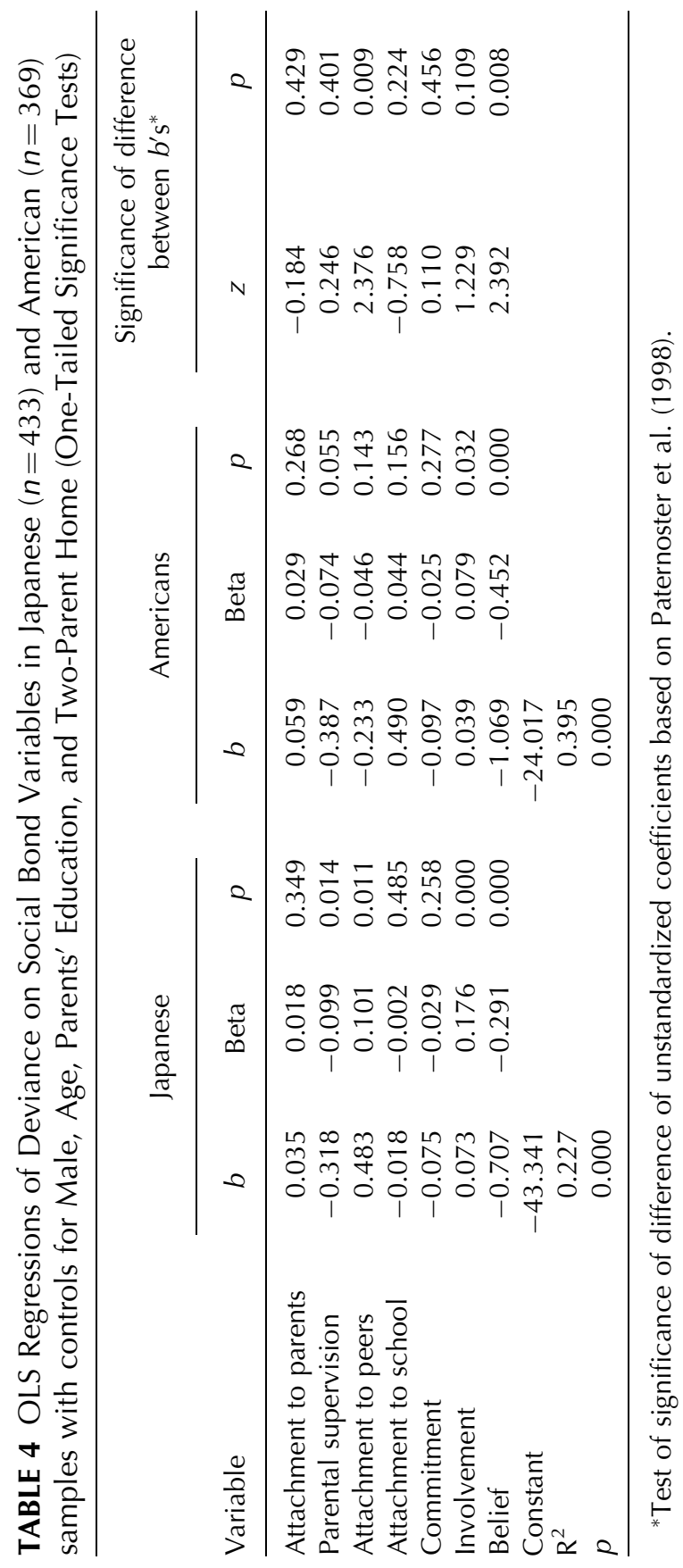


exception of Belief and Parental Supervision, the social bond variables do not have the theoretically expected inverse effects in the sample as a whole or among the Japanese and the Americans considered separately.

\section{CONCLUSION}

The literature we have examined and our own research findings generate four important implications that will be discussed in detail. First, they demonstrate with a unique data set what others have observed in different kinds of data, that is, Japanese, compared to Americans, are more compliant with norms. Second, the greater compliance among the Japanese, at least for our college student samples, cannot be attributed to their stronger bonds to conventional society, as that concept was defined by Hirschi (1969), because, in fact, the Japanese students appear to be more weakly bonded along nearly all the dimensions of social bond identified in his social control theory. Thus, Hirschi's social control theory failed to account for the gap in deviance between our samples of Japanese and American college students. Third, the social bond variables, with one notable exception, appear to have similar effects on self-reported deviance among Japanese as among Americans. Thus, our analysis provides some support for the generalizability of Hirschi's social control theory to non-Western culture. Fourth, however, in our data, those effects do not provide strong support for Hirschi's (1969) social control theory of deviance.

Our study found evidence to support the popular notion that Japanese are more conforming and less deviant than Americans. From official crime statistics (e.g., Adler 1983), the lower crime rate in Japan has been widely recognized and has in fact played a key role in Braithwaite's (1989) development of his theory of reintegrative shaming. More recently, comparative victimization surveys (Dussich et al. 2001; Gruszczynska 2002) have confirmed that rates of serious crimes are lower in Japan than in the United States. Our survey data, relying on self-reports of less serious forms of crime and deviance, although it is a sample of a more conforming group, provide new evidence that Japanese are more compliant than Americans in the types of transgressions typically included in such survey research (e.g., vandalism, petty 
theft, driving a car or motorcycle while under the influence of alcohol). To our knowledge, the only somewhat similar evidence is the comparative study of rule violations in the workplace by Kobayashi (Kobayashi and Grasmick 2002, 2003; Kobayashi et al. 2001), which reports lower levels of workplace deviance (e.g., "calling in sick" when not really sick, taking breaks longer than authorized) among Japanese workers compared to a similar sample of American workers.

The tendency for Japanese college students to be more compliant is not only significant in our data but also is substantial. With controls for age, family socioeconomic status, and family structure (see Table 1), the effect of being Japanese on reducing self-reported deviance $(\beta=-.310)$ is nearly as strong as the effect of being male on increasing it $(\beta=.335)$, and in typical studies of self-reported deviance in the United States, gender usually is the strongest predictor. While gender still trumps culture in our analysis, it does so by only a small margin. And while the direct effect of culture is significant, the effects of family socioeconomic status and family structure are not.

Second, contrary to our hypothesis, we found that the greater compliance among Japanese cannot be attributed to stronger bonds to conventional society, because the Japanese students overall had much weaker social bonds than the American students. The longstanding literature on the collectivistic nature of Japanese society, exemplified in Benedict's (1946) The Chrysanthemum and the Sword and in more recent quantitative research (e.g., Gudykunst et al. 1996) seemed to us to resemble Hirschi's (1969) description of a strong bond to conventional society. The parallel led us to predict that Japanese respondents in our survey would score lower than Americans on self-reported deviance because they have stronger social bonds - attachment, commitment, involvement, and belief in the legitimacy of law. Because of criticism of how these variables have been measured in much of the research testing the theory (Kempf 1993), we tried to remain loyal to Hirschi's original measures in our English version of the questionnaire and in its Japanese translation. What we found is the opposite of our expectations (see Table 2). Japanese college students, in fact, score significantly lower than American students on nearly all of the social bond variables. 
The weaker bonds among Japanese college students, compared to Americans, might be explained in light of recent observations concerning the current status of youth in Japan. The issue surfaced in Japan in 1996 when the Japanese sociologist Masahiro Yamada published The Era of Parasite Singles, detailing a phenomenon that was becoming apparent to many Japanese parents: their children, at an age when they should be entering adult roles, were not doing so. Instead, their grown children continued to live at home, did not marry, and did not obtain full-time employment or begin careers. Rather than establishing their own residences and nuclear families, they lived with their parents (like a "parasite") who provided the bulk of their economic resources. As the title of Yamada's book might suggest, elder Japanese saw this as a character flaw in this younger generation. As reported by Cabinet Office of Japan (2003), an increase in the number and overall proportion of Freeter (a Japanese word for youth who are not students but have only part-time employment), the lower proportion of high school and college graduates who get full-time jobs upon graduation, and an increase in the number of NEET (Not in Education, Employment, or Training, a word created by the British government) also attests to this downward trend among Japanese youth.

Subsequent Japanese scholars (e.g., Masamura 2005; Miyamoto 2002; Nihon Keizai Shinbun 2005; Okubo 2002; Sugimoto 2003) have argued that economic and cultural forces, some global and some unique to Japan, have produced a generation of young adults, now known as Generation $Y$ in Japan, whose future looks quite bleak and who have good reason not to feel a strong bond to the conventional social order. Unlike the Japanese baby-boomers, Generation $\mathrm{Y}$ is experiencing neither the period of economic prosperity of the 1960s and the 1970s nor the Japanese bubble economy of the late 1980s. By the time the front edge of Generation Y graduated from high school in 1992, the Japanese economy already was in decline and has not recovered to this day. For this reason, the New York Times recently referred to this generation as the first group of Japanese since World War II to not experience economic prosperity (Nihon Keizai Shinbun 2005).

Reports by the Cabinet Office, Government of Japan (2006) suggest possible signs of the beginning of an 
economic recovery in the past couple of years since our data were collected in 2003, although not all observers agree with the government's assessment (Nikkei Net 2006). In our data, the Japanese college students, compared to their American counterparts, are significantly more compliant, but at the same time they are significantly less attached to conventional others, less committed to conventional goals, and less involved in conventional activities. These results indicate that Hirschi's social control theory fails to explain the gap in deviance between Japan and the United States and some other theory or theories of deviant behavior will be needed to explain the lower levels of self-reported deviance in the Japanese sample.

Third, we did explore the possibility that variables from Hirschi's control theory of deviance do not have similar effects on self-reported deviance among Japanese students as among Americans students. But for the most part they do, thus providing support for the applicability of Hirschi's social control theory in non-Western culture. When the two samples are analyzed separately, we do not find consistent evidence that social bond variables predict deviance among Japanese any differently than they do among Americans. We do find that belief in the legitimacy of the law has a significantly weaker inverse effect on deviance among the Japanese students than among the Americans. But this difference is not dramatic. Furthermore, for both the Japanese and the American samples, the effect of the belief variable is inverse and significant and the strongest predictor of deviance among the social bond variables.

But a glaring exception occurs concerning the role of attachment to peers. In the Japanese sample, attachment to peers, as Hirschi (1969) defined it, actually has a significant positive effect on deviance, contrary to his argument. In the American sample, on the other hand, the effect of attachment to peers is negative, as the theory predicts, but fails to achieve significance. A positive effect of attachment to peers on deviance also has been observed by Hwang and Akers (2003) in South Korea. Our additional evidence from Japan might suggest a pattern in Asian societies important not only to control theory - which focuses on the effect of peers - but other theories as well, especially social learning theory-which emphasizes the role of peers as a factor in deviant behavior. 
Our results further attest to the need for the examination of social learning variables, such as peer's deviance, in crosscultural studies like ours to examine the possible differences in the effects of attachment to conventional peers versus delinquent peers on deviant behaviors across culture.

One possible explanation for the different effects of attachment to peers on deviance among Japanese and American students might be that in some societies Hirschi's (1969) notion that attachment to others is a unidimensional phenomenon is not applicable. Hirschi assumes that those who are attached to their parents also will be attached to their peers - that those who are unattached to both will be the most noncompliant. Doi $(1971,1985)$ has argued that socialization of children in Japan creates an even stronger sense of emotional dependence on parents than in the United States. The bond between child and parent becomes so strong that attachment to peers is difficult and might only occur when the bond to parents is loosened and youth begin to stray from parental expectations (for a similar argument concerning China, see Zhang and Messner 1995).

If this is so, then we might expect to find, contrary to Hirschi's formulation, a negative relationship between attachment to parents and attachment to peers among Japanese, but a positive relationship among Americans. We considered this possibility by computing the partial correlations for Japanese and for American students between attachment to parents and attachment to peers, with controls for age, gender, socioeconomic status, and family structure. Contrary to our expectation, but consistent with Hirschi's views, however, the partial correlations are positive and significant in Japan $(r=.125)$ and in the United States $(r=.147)$. The question of why attachment to peers in Japan operates in the opposite direction predicted by Hirschi (1969) remains open for future research.

Finally, we found that even if Japanese students would have scored higher than Americans on the social bond variables, as we initially had predicted, it is unlikely that this theory could have accounted for the gap in deviance between Japanese and Americans. That is because the variables from Hirschi's social control theory in our analysis perform rather poorly as predictors of deviance when the samples are combined (Table 3) or analyzed separately (Table 4). The only 
variables to operate consistently and as predicted by theory are parental supervision and belief in the legitimacy of the law. Involvement in conventional activities, contrary to the theory but consistent with other studies (Chaiken 2000; Ploeger 1997; Yamamoto 2005) including Hirschi's (1969) own, has a significant positive effect on deviance. Commitment to conventional goals and the three dimensions of attachment-to parents, peers, and-simply do not appear to inhibit deviant behavior in our data. Thus, while social bond variables behave similarly in explaining deviant behaviors of both Japanese and American samples, it seems that they are behaving equally badly as predictors of deviance, such that it is quite understandable that they thus failed to account for the gap in deviance between the two countries.

It should be noted that one of the limitations of our study is the use of a sample that consists of the relatively more conforming and less deviant groups of college students. It is therefore possible that our dependent and theoretical variables lack strong variation among the sample, resulting in weaker relationships among them. The conclusion, therefore, that Hirschi's (1969) control theory of deviance fails to explain the lower level of deviance among Japanese compared to Americans might be premature. However, it is also important to note that even among the relatively nondeviant group of college students we still find a significant difference in level of deviance between these two countries. If Hirschi's (1969) theory is generalizable to all groups of individuals, then it should be able to explain at least some such differences in the levels of deviance between the two groups.

The findings concerning the poor explanatory power of Hirschi's (1969) social control theory-within group and between groups differences in deviance - are consistent with the summary of research provided by Akers and Sellers (2004:122) who conclude that "the magnitude of the relationships between social bonding and deviant behavior has ranged from moderate to low." In our data, only the external constraints imposed by parents (i.e., parental supervision) and the internalization of legal norms (i.e., belief in the legitimacy of law) are significant predictors of self-reported deviance for both the Japanese and American students. In our research, however, differences between Japanese and 
Americans in levels of these bonds do not account for their difference in levels of deviant behavior. The fact remains that Japanese seem more compliant with social norms than Americans, a fact confirmed with our unique cross-cultural survey data. Our conclusion must be that the explanation for this difference needs to be found somewhere other than in Hirschi's (1969) control theory of deviance.

\section{REFERENCES}

Abegglen, James. G. 1958. The Japanese Factory: Aspects of Its Social Organization. Glencoe, IL: Free Press.

Adler, Freda. 1983. Nations Not Obsessed with Crime. Littleton, CO: Fred B Rothman.

Adler, Freda, Gerhard O. Mueller, and William S. Laufer. 2004. Criminology and the Criminal Justice System (5th ed.). New York: McGraw-Hill.

Akers, Ronald L. and Christine S. Sellers. 2004. Criminological Theories: Introduction, Evaluation, and Application (4th ed.). Los Angeles, CA: Roxbury Publishing Company.

Ball-Rokeach, Sandra J., Milton Rokeach, and Joel W. Grube. 1984. The Great American Values Test. New York: Free Press.

Bellah, Robert N., Richard Madsen, William M., Sullivan, Ann Swidler, and Steven M. Tipton, eds. 1985. Habits of the Heart: Individualism and Commitment in American Life. Berkeley, CA: University of California Press.

Benedict, Ruth. 1946. The Chrysanthemum and the Sword: Patterns of Japanese Culture. Boston, MA: Houghton Mifflin.

Bradshaw, York W. and Michael Wallace. 1996. Global Inequalities. Thousand Oaks, CA: Pine Forge Press.

Braithwaite, John. 1989. Crime, Shame, and Reintegration. New York: Cambridge University Press.

Cabinet Office of Japan, ed. 2003. Kokumin Seikatsu Hakusyo: Defre to Seikatsu-Jyakunen Freeter no Ima [Statistics of Quality of Life: Deflation and Life - Young Freeter Today]. Tokyo: Administrative Office of Japan.

Chaiken, Marcia R. 2000. "Violent Neighborhoods, Violent Kids." Juvenile Justice Bulletin. Washington, DC: U.S. Department of Justice, Office of Justice Programs, Office of Juvenile Justice and Delinquency Prevention. Available at (http://www.ncjrs.gov/pdffiles1/ojjdp/178248. pdf) (access January 20, 2006).

Chapple, Constance L., Julia A. McQuillan, and Terceira A. Berdahl. 2005. "Gender, Social Bonds, and Delinquency: A Comparison of Boy's and Girl's Models." Social Science Research 34:357-383. 
Cole, George F. and Christopher E. Smith. 2001. The American System of Criminal Justice (9th ed.). Belmont, CA: Wadsworth/Thompson Learning.

DeGooyer, Matt J. 1992. "A Comparison of Self-Concepts in Japan and the United States." Pp. 279-288. In Innovations in Cross-Cultural Psychology, edited by S. Iwawaki and Y. Kashima. Netherlands: Swets and Zeitlinger Publishers.

Doi, Takeo. 1971. The Anatomy of Dependence. New York: Kodansha International.

Doi, Takeo. 1985. The Anatomy of Self. New York: Kodansha International.

Dussich, John P. J., Paul C. Friday, Takayuki Okada, Akira Yamagami, and Richard D. Knutden. 2001. Different Responses to Violence in Japan and America. Monsey, NY: Criminal Justice Press.

Gottfredson, Michael R. and Travis Hirschi. 1990. A General Theory of Crime. Paulo Alto, CA: Stanford University Press.

Grasmick, Harold G. and Emiko Kobayashi. 2002. "Workplace Deviance in Japan: Applying an Extended Model of Deterrence." Deviant Behavior 23:21-43.

Gruszczynska, Beata. 2002. "Cross-National Perspectives of Violent Victimization Risk." Pp. 213-226. In Crime Victimization in Comparative Perspective: Results from the International Crime Victims Survey, 1989-2000, edited by P. Nieuwbeerta. Amsterdam, Netherlands: Boom Juridische uitgevers.

Gudykunst, William B., Yuko Matsumoto, Stella Ting-Toomey, Tsukasa Nishida, Kwangsu Kim, and Sam Heyman. 1996. "The Influence of Cultural Individualism-Collectivism, Self-Constructs, and Individual Values on Communication Styles Across Cultures." Human Communication Research 22:510-543.

Hendry, Joy. 1989. Understanding Japanese Society. New York: Routledge. Hirschi, Travis. 1969. Causes of Delinquency. Edison, NJ: Transaction Publishers.

Hofstede, Geert. 1980. Culture's Consequences: International Differences in Work-Related Values. Thousand Oaks, CA: Sage Publications.

Hofstede, Geert. 1984. Culture's Consequences: International Differences in Work-related Values (Abridged ed.). Thousand Oaks, CA: Sage Publications.

Hofstede, Geert. 1991. Cultures and Organizations: Software of the Mind. London: McGraw-Hill.

Hofstede, Geert. 2001. Culture's Consequences: Comparing Values, Behaviors, Institutions, and Organizations across Nations (2nd ed.). Thousand Oaks, CA: Sage Publications.

Hofstede, Geert and Geat Jan Hofstede. 2004. Cultures and Organizations: Software of the Mind. London: McGraw-Hill.

Hofstede, Geert and Michael H. Bond. 1984. "Hofstede's Cultural Dimensions: An Independent Validating Using Rokeach's Value Survey." Journal of Cross-Cultural Psychology 15:417-433. 
Hwang Sunghyun and Ronald L. Akers. 2003. "Substance Use by Korean Adolescents: A Cross-Cultural Test of Social Learning, Social Bonding, and Self-Control Theories." Pp. 39-63. In Social Learning Theory and the Explanation of Crime: A Guide for the New Century, edited by R.

L. Akers and G. F. Gary. Edison, NJ: Transaction Publishers.

Kawasaki, Ichiro. 1969. Japan Unmasked. Rutland, VT: Tuttle Co.

Kempf, Kimberly. 1993. "The Empirical Status of Hirschi's Social Control Theory." Pp. 143-185. In New Directions in Criminology (Vol. 4): Advances in Criminological Theory, edited by F. Adler and W. S. aufer. Edison, NJ: Transaction Publishers.

Kerbo, Harold R. and John A. McKinstry. 1995. Who Rules Japan: The Inner Circles of Economic and Political Power. CT: Praeger Publishers.

Kobayashi, Emiko and Harold G. Grasmick. 2002. "Workers' Decision to Comply: Comparison of the Perceived Threats of Managerial Sanctions, Embarrassment, and Shame in Japan and the United States." Journal of Language, Culture, and Communication 4:1-12.

Kobayashi, Emiko and Harold G. Grasmick. 2003. "Punishment for Noncompliance and Reward for Compliance: A Comparison of Japanese and American Workers." NUCB Journal of Economics and Information Science 47:125-136.

Kobayashi, Emiko, Harold G. Grasmick, and Gustav Friedrich. 2001. "A Cross-Cultural Study of Shame, Embarrassment, and Management Sanctions as Deterrents to Noncompliance with Organizational Rules." Communication Research Reports 18:105-117.

Komiya, Nobuo. 1999. "A Cultural Study of the Low Crime Rate in Japan." British Journal of Criminology 39:369-390.

Kornhauser, Ruth Rosner. 1978. Social Sources of Delinquency: An Appraisal of Analytic Models. Chicago: University of Chicago Press.

Lie, John. 2001. Multiethnic Japan. Cambridge, MA: Harvard University Press.

Lowell, Percival. 1888. The Soul of the Far East. Cambridge, MA: Houghton Mifflin and Company.

Markus, Hazel R. and Shinobu Kitayama. 1991. "Culture and the Self: Implications for Cognition, Emotion, and Motivation." Psychological Review 98:224-253.

Masamura, Kimihiro. 2005. Keizai ga Syakai wo Houkai Suru [When Economy Destroys Society]. Tokyo: NTT Press.

Matsumoto, David and Linda Juang. 2004. Culture and Psychology. Belmont, CA: Wadsworth/Thompson Learning.

Matsumoto, David, Tsutomu Kudoh, and Sachiko Takeuchi. 1996. "Changing Patterns of Individualism and Collectivism in the United States and Japan." Culture and Psychology 2:77-107.

Matsumoto, David, Michelle D. Weissman, Ken Preston, Bonny R. Brown, and Cenita Kupperbusch 1997. "Context-Specific Measurement of Individualism-Collectivism on the Individual Level: The IC Interpersonal 
Assessment Inventory (ICIAI)." Journal of Cross-Cultural Psychology 28:743-767.

Miller, Alan S. 1992. "Predicting Nonconventional Religious Affiliation in Tokyo: A Control Theory Application." Social Forces 71:397-410.

Ministry of Education, Culture, Sports, Science, and Technology. 2003. "Gakko-su, Zaigakusya-su, Kyoushyokuin-su [The Number of Schools, Students, Teachers and Non-teaching Staffs]." Available at (http:// www.mext.go.jp/b_menu/toukei/002/002b/16/xIs/001.xls) (accessed January 19, 2006).

Ministry of Public Management, Home., Affairs, Posts, and Telecommunications, Japan. 1995. "Kokuseki Betsu Touroku Gakikokujin Su [The Number of Registered Foreigners by Nationality]." Available at (http:// www.stat.go.jp/data/nihon/zuhyou/n0202900.xls) (accessed January 19, 2006).

Miyamoto, Michiko. 2002. Wakamono ga "Syakaiteki Jyakusha" ni Tenraku Suru [The Fall of Youths into the Class of "Unfortunates" of a Society]. Tokyo: Yosen Co.

Nakane, Chie. 1970. Japanese Society. Berkeley, CA: University of California Press.

Nihon Keizai Shinbun [Japanese Newspaper of Economics], ed. 2005. Generation-Y. Tokyo: Nihon Keizai Sinbun.

Nikkei Net. 2006. "Keiki Watcher Cyousa [Investigation of Economic Trends]." Available at (http://www.nikkei.co.jp/keiki/keikiy/) (accessed March 10, 2006).

Okubo, Yukio. 2002. Sinsotsu Mugyou [Newly Graduated and Unemployed]. Tokyo: Toyokeizai.

Paternoster, Raymond, Robert Brame, Paul Mazerolle, and Alex Piquero. 1998. "Using the Correct Statistical Test for the Equality of Regression Coefficients." Criminology 36:859-866.

Ploeger, Matthew. 1997. "Youth Employment and Delinquency: Reconsidering a Problematic Relationship." Criminology 35: 659-675.

Reckless, Walter C. 1967. The Crime Problem (4th ed.) New York: Appleton-Century-Crofts.

Roberts, Aki and Gary LaFree. 2001. "The Role of Declining Economic Stress in Explaining Japan's Remarkable Postwar Crime Decreases, 1951 to 1997." Japanese Journal of Sociological Criminology 26:11-34.

Roberts, Aki and Gary LaFree. 2004. "Explaining Japan's Postwar Violent Crime Trends." Criminology 42:179-209.

Rokeach, Milton. 1973. The Nature of Human Values. New York: Free Press.

Saito, Tomonori. 2002. "Association with Delinquent Peers, Social Bonding, and Delinquent Behavior: Testing the Differential 
Reinforcement Hypothesis and Social Control Theory." Kyoiku-Shakigaku Kenkyu [The Journal of Educational Sociology] 71:131-150.

Schwartz, Shalom H. 1990. "Individualism-Collectivism: Critique and Proposed Refinements." Journal of Cross-Cultural Psychology 21:139-157.

Schwartz, Shalom H. 1992. "Universals in the Content and Structure of Values." Pp. 1-65. In Advances in Experimental Social Psychology, Vol. 25, edited by M. Zanna. New York: Academic Press.

Shoemaker, Donald J. 1994. "Male-Female Delinquency in the Philippines: A Comparative Analysis." Youth and Society 25:299-329.

Sugimoto, Yoshio. 2003. An Introduction to Japanese Society (2nd ed). New York: Cambridge University Press.

Tanioka, Ichiro and Daniel Glaser. 1991. "School Uniforms, Routine Activities, and the Social Control of Delinquency in Japan." Youth and Society 23:50-75.

Thornton, Robert Y. and Katsuya Endo. 1992. Preventing Crime in America and Japan: A Comparative Study. Armonk, NY: M E. Sharpe, Inc.

Tittle, Charles R. and Ekaterina V. Botchkovar. 2005. "The Generality and Hegemony of Self-Control Theory: A Comparison of Russian and US Adults." Social Science Research 34:703-731.

Triandis, Harry C. 1988. "Collectivism and Individualism: A Reconceptulization of a Basic Concept in Cross Cultural Psychology." Pp. 60-95. In Personality, Attitudes, and Cognitions, edited by G. K. Verna and C. Bargley. London: Macmillan.

Triandis, Harry C. 1990. "Cross-Cultural Studies of IndividualismCollectivism." Pp. 41-133. In Nebraska Symposium on Motivation 1989, Vol. 37, edited by J. Berman. Lincoln, NE: University of Nebraska Press.

Triandis, Harry C. 1995. Individualism and Collectivism. Boulder, CO: Westview.

Triandis, Harry C. 1999. "Cross-Cultural Psychology." Asian Journal of Social Psychology 2:127-143.

Vazsonyi, Alexander T., Janice E. Clifford Wittekind, Lara M. Belliston, and Timothy D. Van Loh. 2004. "Extending the General Theory of Crime to 'The East:' Low Self-Control in Japanese Late Adolescents." Journal of Quantitative Criminology 20:189-216.

Wang, Gabe T., Hengrui Qiao, Shaowei Hong, and Jie Zhang. 2002. "Adolescent Social Bond, Self-Control, and Deviant Behavior in China." International Journal of Contemporary Sociology 39:52-68.

Yamada, Masahiro. 1996. Parasaito-singuru no Jidai [The Era of Parasite Singles]. Tokyo: Chikuma Shinsyo.

Yamamoto, Isao. 2005. "Does a Part-Time Job Act as a Social Bond to Prevent Juvenile Delinquency?" Japanese Journal of Sociological Criminology 30:138-150. 
Zhang, Lening and Steven F. Messner. 1995. "Family Deviance and Delinquency in China." Criminology 33:359-387.

Zhang, Lening and Steven F. Messner. 1996. "School Attachment and Official Delinquency Status in the People's Republic of China." Sociological Forum 11:285-303.

Post-print standardized by MSL Academic Endeavors, the imprint of the Michael Schwartz Library at Cleveland State University, 2014 